\title{
Article \\ Enhanced Photocatalytic Removal of Cyanotoxins by Al-Doped ZnO Nanoparticles with Visible-LED Irradiation
}

\author{
Majdi Benamara $^{1}\left(\mathbb{D}\right.$, Elvira Gómez ${ }^{2,3}\left(\mathbb{D}\right.$, Ramzi Dhahri $^{4,5, *}$ and Albert Serrà ${ }^{2,3, *(D)}$ \\ 1 Laboratory of Physics of Materials and Nanomaterials Applied at Environment (LaPhyMNE), \\ Faculty of Sciences, University of Gabes, Erriadh Manara Zrig, 6072 Gabes, Tunisia; \\ majdibenamara1@gmail.com \\ 2 Thin Films and Nanostructures Electrodeposition Group (GE-CPN), Department of Materials Science and \\ Physical Chemistry, University of Barcelona, Martí i Franquès 1, E-08028 Barcelona, Spain; e.gomez@ub.edu \\ 3 Institute of Nanoscience and Nanotechnology (IN2UB), University of Barcelona, E-08028 Barcelona, Spain \\ 4 Department of Engineering, University of Messina, 98166 Messina, Italy \\ 5 ITE Sarl Laboratories for Analysis Water, Processing and Packaging Industry (ITE), Moukondo, \\ Brazzaville, Congo \\ * Correspondence: r_dhahri@yahoo.fr (R.D.); a.serra@ub.edu (A.S.)
}

\section{check for}

updates

Citation: Benamara, M.; Gómez, E.; Dhahri, R.; Serrà, A. Enhanced

Photocatalytic Removal of

Cyanotoxins by Al-Doped ZnO

Nanoparticles with Visible-LED

Irradiation. Toxins 2021, 13, 66.

https://doi.org/10.3390/toxins13010066

Received: 11 November 2020

Accepted: 13 January 2021

Published: 17 January 2021

Publisher's Note: MDPI stays neutral with regard to jurisdictional claims in published maps and institutional affiliations.

Copyright: (C) 2021 by the authors. Licensee MDPI, Basel, Switzerland. This article is an open access article distributed under the terms and conditions of the Creative Commons Attribution (CC BY) license (https:// creativecommons.org/licenses/by/ $4.0 /)$.

\begin{abstract}
The ZnO-based visible-LED photocatalytic degradation and mineralization of two typical cyanotoxins, microcystin-LR (MC-LR), and anatoxin-A were examined. Al-doped ZnO nanoparticle photocatalysts, in $\mathrm{Al}: \mathrm{Zn}$ ratios between 0 and 5 at.\%, were prepared via sol-gel method and exhaustively characterized by $\mathrm{X}$-ray diffraction, transmission electron microscopy, UV-vis diffuse reflectance spectroscopy, photoluminescence spectroscopy, and nitrogen adsorption-desorption isotherms. With both cyanotoxins, increasing the $\mathrm{Al}$ content enhances the degradation kinetics, hence the use of nanoparticles with 5 at.\% Al content (A5ZO). The dosage affected both cyanotoxins similarly, and the photocatalytic degradation kinetics improved with photocatalyst concentrations between 0.5 and $1.0 \mathrm{~g} \mathrm{~L}^{-1}$. Nevertheless, the $\mathrm{pH}$ study revealed that the chemical state of a species decisively facilitates the mutual interaction of cyanotoxin and photocatalysts. A5ZO nanoparticles achieved better outcomes than other photocatalysts to date, and after $180 \mathrm{~min}$, the mineralization of anatoxin-A was virtually complete in weak alkaline medium, whereas only $45 \%$ of MC-LR was in neutral conditions. Moreover, photocatalyst reusability is clear for anatoxin-A, but it is adversely affected for MC-LR.
\end{abstract}

Keywords: cyanotoxins; microcystin-LR; anatoxin-(a); photocatalysis; ZnO-doped nanoparticles; visible light; LEDs

Key Contribution: The efficient mineralization of cyanotoxins is proposed, using Al-doped $\mathrm{ZnO}$ nanoparticles under visible-LED irradiation. Concerning photocatalytic performance, the Al-doped $\mathrm{ZnO}$ nanoparticles are equal to, if not better than, the most competitive state-of-the-art photocatalysts for cyanotoxin mineralization.

\section{Introduction}

Cyanobacteria are common prokaryotic photosynthetic inhabitants of bodies of water worldwide that can survive in extreme environmental conditions and through dramatic changes in salinity, temperature, desiccation, and irradiance [1,2]. Under favorable conditions, cyanobacteria can achieve high rates of population density in water and thus facilitate the formation of dense blooms that can significantly compromise water quality (e.g., increase the turbidity of freshwater and change its odor and taste) [3-5]. Even so, the greater threat to freshwater resources posed by cyanobacterial blooms is the formation of cyanotoxins, which, in naturally occurring concentrations, are highly toxic to plants, invertebrates, and vertebrates [6,7]. Because the ingestion of cyanotoxins generally causes liver, digestive, and neurological diseases, their presence could make water too dangerous 
for recreational activities, drinking-water purification, fisheries, and, more broadly, human health $[1,2,8,9]$.

Cyanotoxins are typically classified as hepatotoxins (e.g., microcystin, nodularin, and cylindrospermopsin), neurotoxins (e.g., anatoxin and saxitoxin), or dermatoxins (e.g., aplysiatoxin), depending on their toxicological effects $[1,2,8,10]$. However, they can also be classified according to their chemical composition-that is, as cyclic peptides (e.g., microcystin and nodularin), alkaloids (e.g., cylindrospermopsin, anatoxin, and saxitoxin), or lipopolysaccharides (e.g., endotoxin). No exhaustive list of cyanotoxins exists, however, and far more could be discovered, pending the identification of cyanobacterial secondary metabolites. Regardless of classification, cyanotoxins generally present a high risk of illness and mortality and rank among the most lethal groups of known biotoxins [8-11].

In recent years, mounting evidence of increased cyanobacterial blooms and cyanotoxins worldwide has raised public awareness of their toxic effects on water use and water quality. Research has shown that the increased prevalence, occurrence, and abundance of cyanobacterial blooms, and, in turn, concentration of cyanotoxins in bodies of water on a global scale, are driven by eutrophication, rising concentrations of atmospheric $\mathrm{CO}_{2}$, and global warming, all of which stem from anthropogenic activities, especially climate change $[2,9,11,12]$. Because more frequent and prolonged blooms are likely to occur worldwide in the coming decades, the global context of the threat urges the development of simple, low-cost strategies and technologies for detoxicating and degrading cyanotoxins that can be readily implemented worldwide [2,9].

Although conventional water-treatment processes, such as coagulation, flocculation, rapid sand filtration, sedimentation, and chlorination, can efficiently remove cyanobacteria and low levels of various cyanotoxins, they cannot completely degrade some cyanotoxins (e.g., anatoxin-A). In the past two decades, the relatively low efficiency of those methods gave way to the use of advanced oxidation processes (AOPs) [9,13-16]. In general, AOPs are based on the mineralization of organic pollutants by highly reactive and non-selective species generated in situ (i.e., $\mathrm{H}_{2} \mathrm{O}_{2}, \cdot \mathrm{OH}, \mathrm{O}_{2} \cdot{ }^{-}$, and $\mathrm{O}_{3}$ ). Among the different species generated, hydroxyl radicals are often considered to be the most important contributors to water decontamination during AOPs $[17,18]$. As a testament to their versatility, AOPs can generate such reactive species by accommodating various processes, especially radiation, oxidation, and catalysis, and even their combination $[9,13,14]$.

Of the various AOPs, heterogeneous photocatalysis, particularly when using $\mathrm{TiO}_{2}-$ based photocatalysts, has emerged as an efficient approach to degrading, and eventually mineralizing, microcystins and cylindrospermopsin by using UV-light irradiation $[9,12,13]$. However, despite considerable efforts to improve $\mathrm{TiO}_{2}$ 's photocatalytic performance in mineralizing cyanotoxins under visible light or sunlight irradiation, usually via doping or surface modification, such laboratory-scale research has rarely assessed the integration of the photocatalysts into photocatalytic reactors [19]. On top of that, few studies have involved investigating the photocatalytic degradation of other cyanotoxins, such as anatoxin-A, or the use of alternative, inexpensive sources of light $[9,13,20,21]$. Importantly, it is clear that photocatalysis does not seem to be the most appropriate way to remove cyanotoxins from a body of water (e.g., reservoirs, lakes, and ponds), but it may be especially relevant for treating water that contains cyanotoxins (and other organic contaminants), which is destined for human, animal, or industrial use.

Research in the future may face formidable challenges with improving the economic, practical, engineering, and environmental quality of full-scale applications that can promote the use of photocatalysis in water-treatment processes [9]. Whereas solar light, despite its advantages, entails the complexity of designing efficient solar photocatalytic reactors and, beyond that, using solar light, a smarter way to facilitate photocatalytic reactor design for full-scale plants could be by using light-emitting diodes (LEDs) as a light source. LEDs are characterized by low energy consumption, which, in turn, reduces the energy consumption of UV or visible lamps; they can also simplify photoreactor designs $[9,13,22]$. 
In our study, a visible-light active $\mathrm{Al}-$ doped $\mathrm{ZnO}$ nanoparticle photocatalyst, synthesized by following a facile, scalable sol-gel new method, was examined for how the Al:Zn ratio affected its morphology, structure, and optoelectronic properties. The photocatalytic activity of the Al-doped $\mathrm{ZnO}$ nanoparticle photocatalyst was evaluated according to its photocatalytic degradation of microcystin-LR (MC-LR) and anatoxin-A, under visibleLED irradiation, compared with the photocatalytic activity of $\mathrm{ZnO}$ and $\mathrm{Al}$-doped $\mathrm{ZnO}$ nanoparticles. The effects of the dosage of photocatalyst and the solution's $\mathrm{pH}$ were also investigated, as were its reusability and chemical and photochemical stability.

\section{Results and Discussion}

Al-doped $\mathrm{ZnO}$ photocatalysts, all synthesized via the sol-gel method, were labeled $\mathrm{A} 0 \mathrm{ZO}, \mathrm{A} 1 \mathrm{ZO}, \mathrm{A} 3 \mathrm{ZO}$, and $\mathrm{A} 5 \mathrm{ZO}$ for $\mathrm{Al}: \mathrm{Zn}$ atomic ratios of $0 \%, 1 \%, 3 \%$, and $5 \%$, respectively. The synthesized materials were characterized by X-ray diffraction (XRD), transmission electron microscopy (TEM), UV-vis diffuse reflectance spectroscopy, photoluminescence (PL) spectroscopy, and nitrogen adsorption-desorption isotherms.

\subsection{Characterization of Photocatalysts}

2.1.1. Microstructural and Morphological Characterization

The diffractogram in Figure 1 illustrates the XRD patterns of Al-doped ZnO (AZO) nanoparticles annealed at $400{ }^{\circ} \mathrm{C}$ and their numerous diffraction peaks. As shown, all peaks had different intensities, which could indicate anisotropic growth. Notably, the peaks corresponded to a reticular plane of (100), (002), (101), (102), (110), (103), (200), (112), and (201) in ZnO's hexagonal structure, with space group P63mc, according to JCPDS no. 01-073-8765. The calculated lattice parameters values $(a, c)$, the concluded unit cell volume $(V)$, the average sizes of the crystallites $(D)$, the micro-deformations $(\varepsilon)$, and the dislocation densities $(\delta)$ are presented in Table 1 [23-26]. Among other results, the smaller average size $(D)$ and higher dislocation density $(\delta)$ of A1ZO indicate its relatively high concentration of structural defects. Structural defects can improve the photocatalytic performance of ZnO-based photocatalysts.
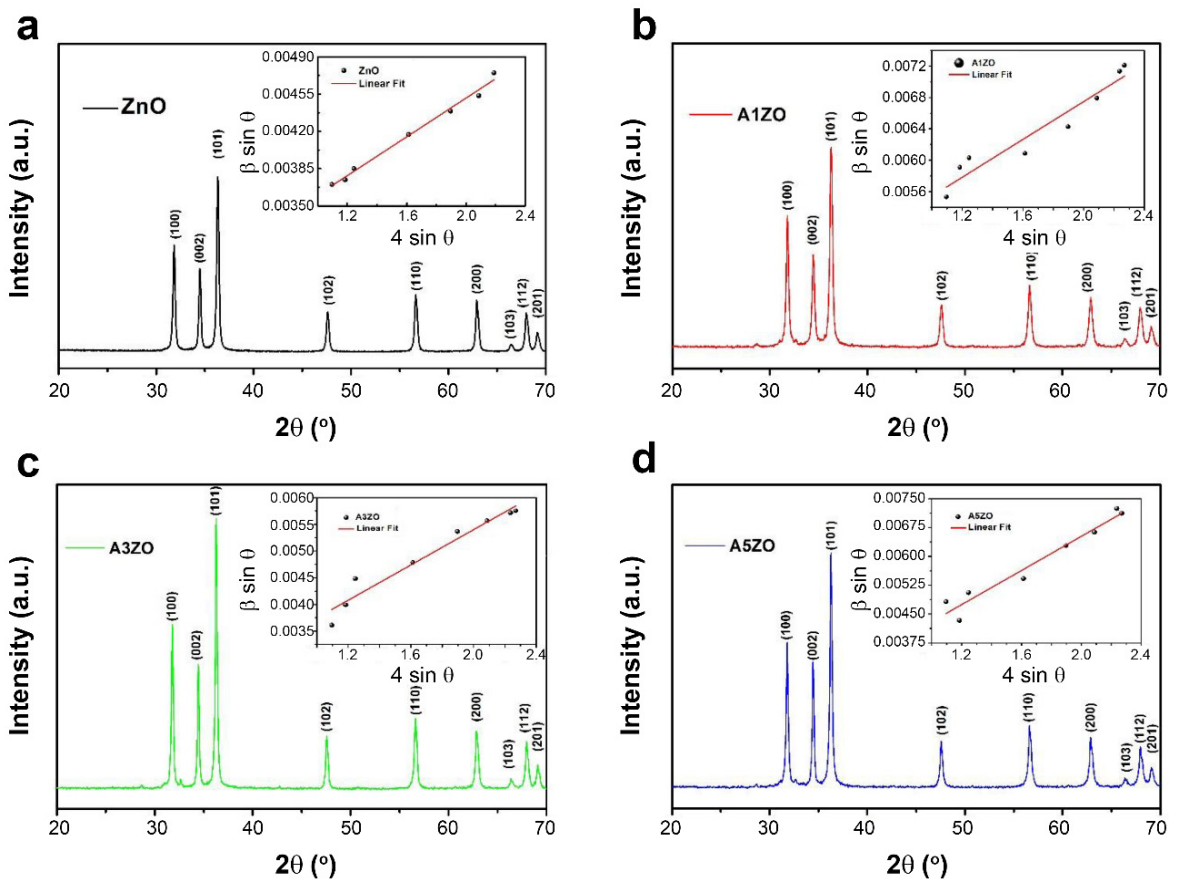

Figure 1. X-ray diffraction patterns of (a) A0ZO, (b) A1ZO, (c) A3ZO, and (d) A5ZO nanopowders with Williamson-Hall plots (inset). 
Table 1. Structural parameters of the AZO samples.

\begin{tabular}{|c|c|c|c|c|c|c|c|}
\hline & $a(\AA)$ & $c(\AA)$ & $V\left(\AA^{3}\right)$ & $D_{W-H}(\mathrm{~nm})$ & $D_{T E M}(\mathrm{~nm})$ & $\varepsilon\left(10^{-4}\right)$ & $\delta\left(10^{-3}\right.$ Line $\left.\times \mathrm{nm}^{-2}\right)$ \\
\hline $\mathrm{A} 0 \mathrm{ZO}$ & 3.244 & 5.195 & 47.338 & 52 & 39 & 9.1 & 81 \\
\hline $\mathrm{A} 1 \mathrm{ZO}$ & 3.246 & 5.201 & 47.465 & 32 & 33 & 12.0 & 174 \\
\hline $\mathrm{A} 3 \mathrm{ZO}$ & 3.245 & 5.200 & 47.431 & 66 & 43 & 16.5 & 116 \\
\hline $\mathrm{A} 5 \mathrm{ZO}$ & 3.245 & 5.199 & 47.423 & 69 & 48 & 22.2 & 148 \\
\hline
\end{tabular}

The distribution of the AZO samples prepared by the sol-gel method by shape and particle size appears in multiple TEM images in Figure 2. Pure $\mathrm{ZnO}$ nanoparticles were widely distributed in terms of size and irregularly in shape. Doping $\mathrm{ZnO}$ with $\mathrm{Al}$, by comparison, produced smaller nanoparticles. Low doping with Al appeared to reduce the size of particles, while higher loadings generated not only more of the small nanoparticles but also nanoparticles greater than $60 \mathrm{~nm}$ in size. The small particles were likely derived from the presence of secondary phases formed during heterogeneous nucleation and the accompanying spontaneous increase in the grain area [27]. For comparison's sake, Table 1 lists the average particle sizes of AZO samples estimated by TEM images. On average, particles in the sample, with low doping (i.e., A1ZO), were smaller than the ones in the pure $\mathrm{ZnO}$ samples and the samples with high doping (i.e., A3ZO and A5ZO).
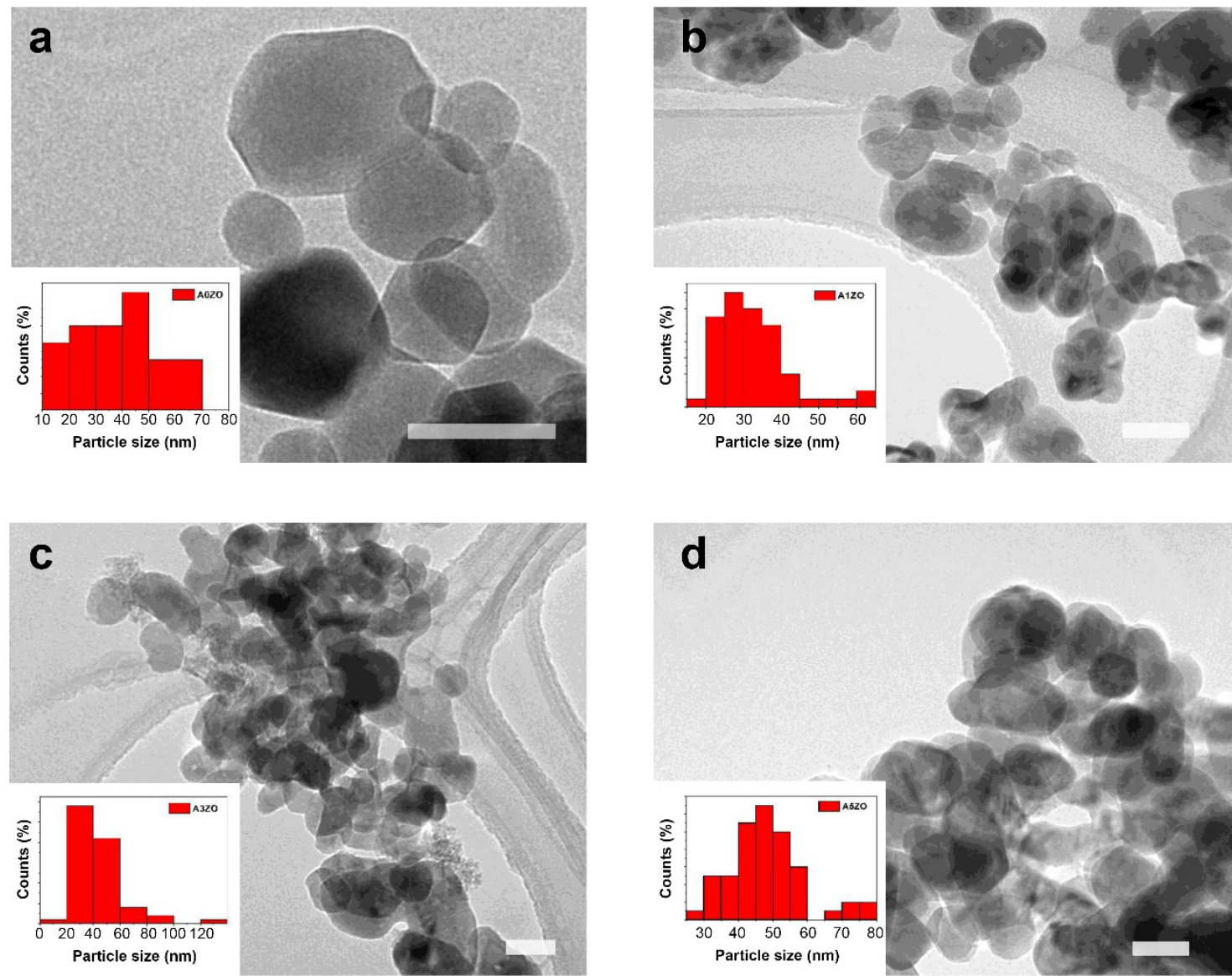

Figure 2. Transmission electron microscopic images and grain sizes distribution of (a) A0ZO, (b) A1ZO, (c) A3ZO, and (d) A5ZO nanopowders. Scale bar: $50 \mathrm{~nm}$.

The surface area of pure $\mathrm{ZnO}$ and $\mathrm{Al}$-doped $\mathrm{ZnO}$ nanopowders was investigated by the BET measurements. The surface areas of pure $\mathrm{ZnO}$ was found to be $11.8 \mathrm{~m}^{2} / \mathrm{g}$. The surface area increased to $16.6,19.2$, and $17.8 \mathrm{~m}^{2} / \mathrm{g}$ when $\mathrm{ZnO}$ was doped with 1 , 3, and 5 at.\% of $\mathrm{Al}$, respectively. The increase in surface area could be accounted for by the change 
of size of the particles. A similar increase in surface areas was observed in other studies involving doping on $\mathrm{ZnO}$ with aluminum.

\subsubsection{Optoelectronic Characterization}

The UV-vis absorption spectra of $\mathrm{ZnO}$ and $\mathrm{AZO}$ are depicted in Figure 3a. Not only were the edge values of AZO nanoparticles blue-shifted relative to $\mathrm{ZnO}$ nanoparticles, but absorbance in the visible region had improved primarily due to deep levels in $\mathrm{ZnO}^{\prime} \mathrm{s}$ bandgap created by the increased concentration of defects. The bandgaps of $\mathrm{ZnO}$ and $\mathrm{AZO}$, determined with an $(\alpha \mathrm{h} v)^{2}$ plot as a function of photon energy, revealed that higher $\mathrm{Al}$ concentrations coincided with lower bandgap energies, which fell from 3.22 to $2.99 \mathrm{eV}$.
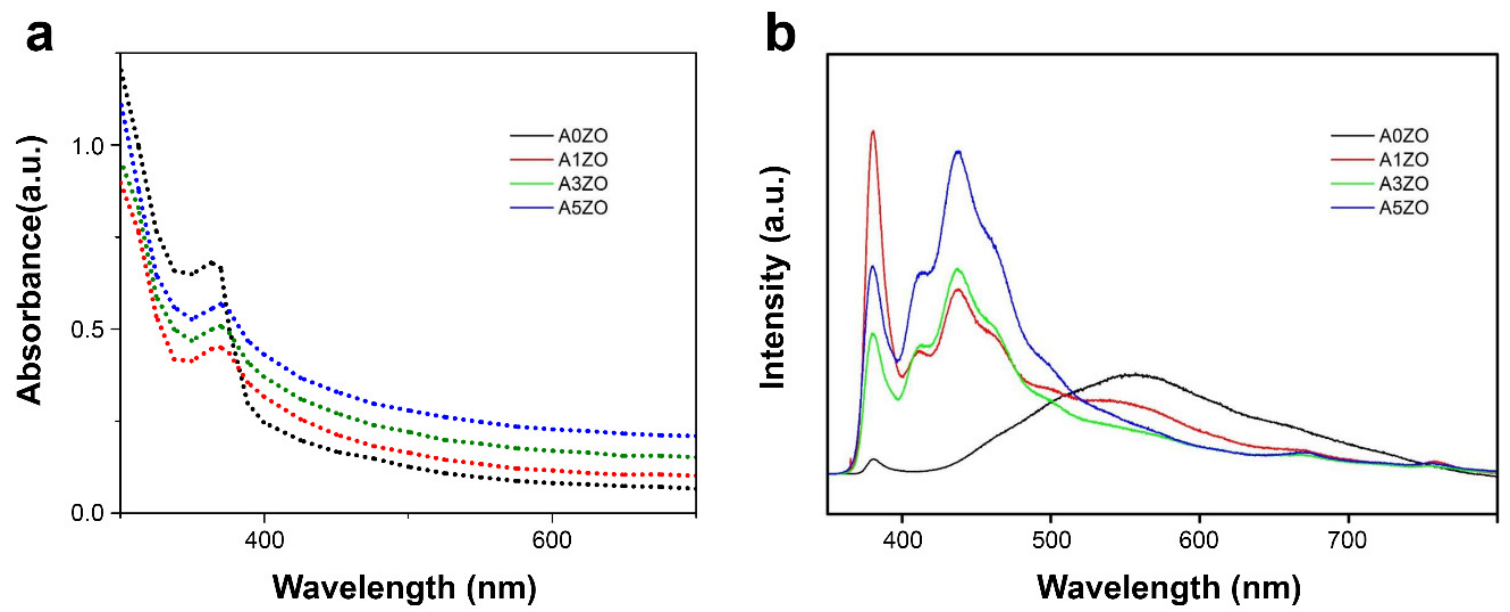

Figure 3. (a) UV-Vis DRS absorption spectra in diffuse reflectance spectroscopy and (b) photoluminescence spectra of ZnO and $\mathrm{Al}$-doped $\mathrm{ZnO}$ nanoparticles at room temperature.

The PL spectra of the pure and Al-doped $\mathrm{ZnO}$ nanopowders appear in Figure $3 \mathrm{~b}$. The spectrum of the reference sample (i.e., pure $\mathrm{ZnO}$ ) showed two bands: a narrow one at $380 \mathrm{~nm}$ of UV emission and a wide one of visible emission at $552 \mathrm{~nm}$. UV emission was used to refer to band-to-band emissions, while PL emissions in the visible-light range were based on emissions attributed to inter-band defects. As such, the wide visible band was attributed to several intrinsic defects, including interstitial zinc $\left(\mathrm{Zn}_{\mathrm{i}}\right)$, oxygen vacancies $\left(\mathrm{V}_{\mathrm{o}}\right)$, and oxygen antisites $\left(\mathrm{O}_{\mathrm{Zn}}\right)$, present in the $\mathrm{ZnO}^{\prime} \mathrm{s}$ structure [28,29].

Beyond that, the PL emission spectra of the $\mathrm{Al}$-doped $\mathrm{ZnO}$ samples and pure $\mathrm{ZnO}$ samples differed in appearance. As the intensity of the green emission band gradually disappeared, the $380 \mathrm{~nm}$ 's emission band increased in intensity. In addition, a new band centered at $437 \mathrm{~nm}$ appeared, which we attributed to the blue emission, possibly from intrinsic defects and/or from the recombination of the donor-acceptor pair linked to the acceptor Al. Altogether, our results suggest that, as Al content increased, so did the intensity of the blue band, whereas the green band's intensity dropped [30].

\subsection{Photocatalytic Degradation of Cyanotoxins}

The photocatalytic activity of $\mathrm{ZnO}$ and $\mathrm{AZO}$ nanoparticle photocatalysts was evaluated in terms of the photocatalytic degradation of MC-LR and anatoxin-A under visibleLED irradiation at $\mathrm{pH}$ 7.0. As shown in Figure 4a,b, the photolytic degradation of both cyanotoxins was negligible during $80 \mathrm{~min}$ of visible-LED irradiation. Prior to investigating the photocatalytic degradation of the cyanotoxins, the time required to attain the adsorption-desorption equilibrium was determined in dark conditions for both the $\mathrm{ZnO}$ and AZO nanoparticle photocatalysts. After $60 \mathrm{~min}$, the adsorption-desorption equilibrium was reached for all of the photocatalysts. Thus, only $5 \pm 1 \%$ and $3 \pm 1 \%$ of MC-LR and anatoxin- $\mathrm{A}$, respectively, could be adsorbed by $\mathrm{ZnO}$ and $\mathrm{AZO}$ nanoparticles in dark conditions. 
a

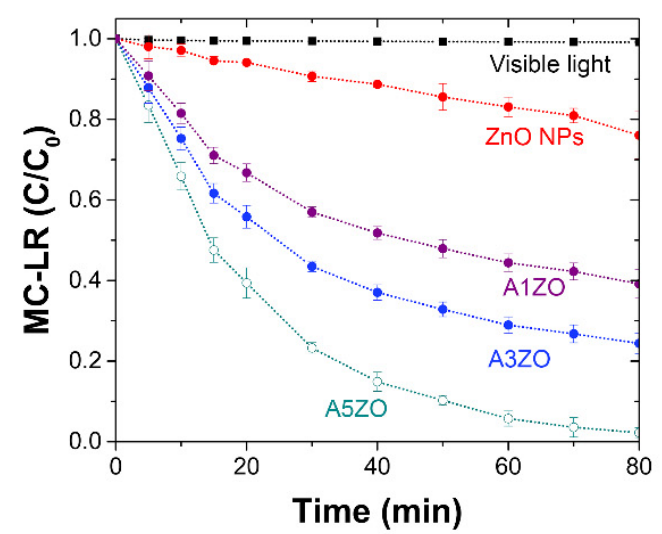

C

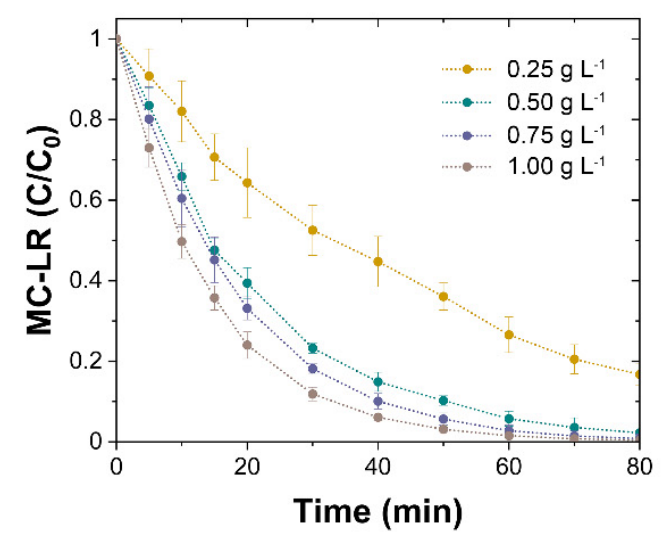

e

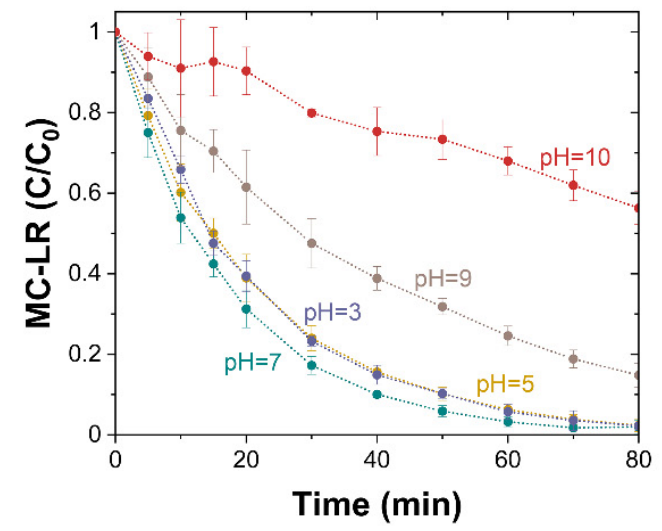

b

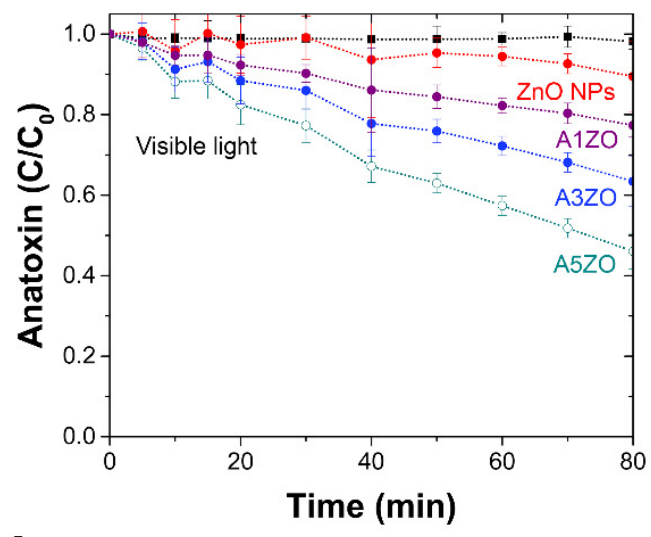

d

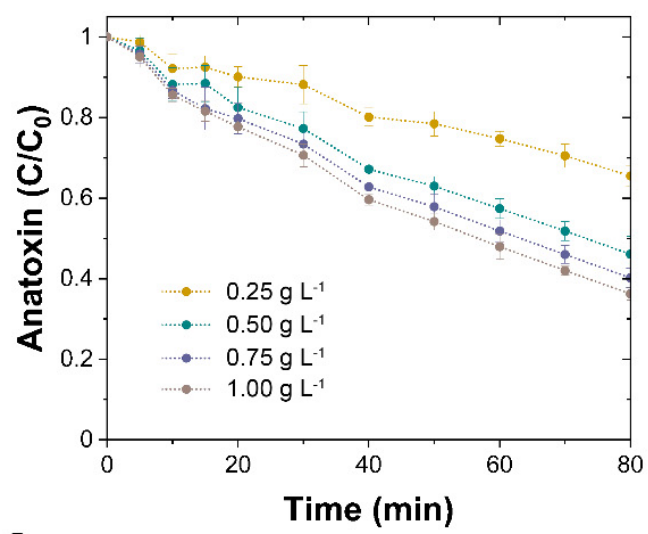

f

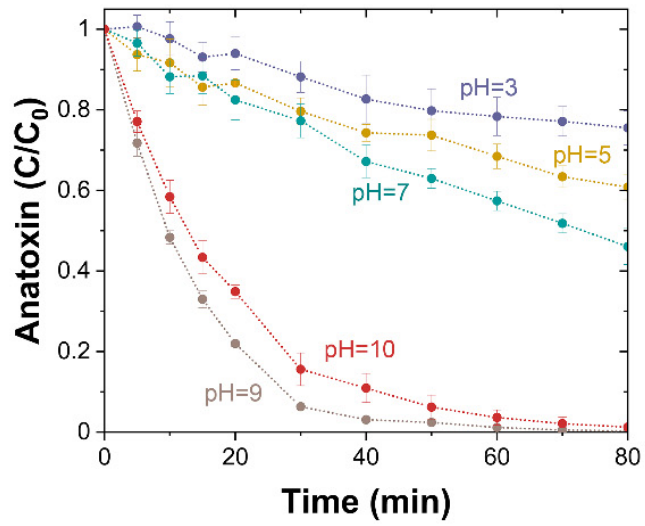

Figure 4. Photocatalytic activity of $\mathrm{ZnO}$ and $\mathrm{AZO}$ nanoparticle photocatalysts (photocatalyst dosage $=0.5 \mathrm{~g} \mathrm{~L}^{-1}$ ) in the photocatalytic degradation of (a) microcystin-LR (MC-LR) and (b) anatoxin-A under visible light-emitting diode (LED) irradiation at $\mathrm{pH} 7.0$ and $20^{\circ} \mathrm{C}$. Effect of A5ZO photocatalyst dosage on the photocatalytic degradation of (c) MC-LR and (d) anatoxin-A under visible LED irradiation at $\mathrm{pH} 7.0$ and $20^{\circ} \mathrm{C}$. Effect of $\mathrm{pH}$ of A5ZO photocatalyst $\left(0.5 \mathrm{~g} \mathrm{~L}^{-1}\right)$ on the photocatalytic degradation of (e) MC-LR and (f) anatoxin-A under visible LED irradiation at $20^{\circ} \mathrm{C}$. Error bars indicate standard deviations of the four replicated experiments.

As shown in Figure 4a,b, pure $\mathrm{ZnO}$ nanoparticles exhibited the least efficiency in removing MC-LR and anatoxin-A—only approximately $24 \pm 3 \%$ and $10 \pm 2 \%$, respectivelywithin $80 \mathrm{~min}$. Moreover, as also shown in Figure 4, as Al doping increased, the photocatalytic degradation achieved by AZO nanoparticles with MC-LR and anatoxin-A increased from $61 \pm 2 \%$ to $98 \pm 2 \%$ and from $23 \pm 2 \%$ to $54 \pm 1 \%$, respectively, probably due to the improved surface area and enhanced visible-light absorption. Al doping enhanced the pho- 
tocatalytic performance in the samples, and, for that reason, A5ZO displayed the highest degradation efficiency (i.e., approximately $98 \pm 2 \%$ and $54 \pm 1 \%$ for MC-LR and anatoxin$\mathrm{A}$, respectively) under the same conditions. The effects of the dosage of photocatalyst and the solution's pH were investigated for the A5ZO nanoparticle photocatalyst only.

The effects the dosage of photocatalyst on the photocatalytic degradation of MC-LR and anatoxin-A under visible LED illumination were systematically assessed by altering the catalyst loading from 0.25 to $1.0 \mathrm{~g} \mathrm{~L}^{-1}$, with all other parameters unchanged. As shown in Figure $4 c, d$, the photocatalytic degradation of both cyanotoxins increased as the dosage of photocatalyst rose from 0.25 to $0.5 \mathrm{~g} \mathrm{~L}^{-1}$ but less so from 0.5 to $1.0 \mathrm{~g} \mathrm{~L}^{-1}$. In turn, increases in dosage further decreased the degradation rate of both cyanotoxins. In that dynamic, increasing the dosage of the photocatalyst creates more sites for actively adsorbing both cyanotoxins and generates highly reactive radicals, which together translate into an increase in photocatalytic degradation. At the same time, high dosages of photocatalysts $\left(>1.0 \mathrm{~g} \mathrm{~L}^{-1}\right)$ hinder the penetration of visible light and can induce the agglomeration of nanoparticles, which together translate into a reduced rate of photocatalytic degradation. Thus, the optimal dosage for enhanced photocatalytic activity was found to range from 0.5 to $1.0 \mathrm{~g} \mathrm{~L}^{-1}$.

The effect of $\mathrm{pH}$ on the photocatalytic degradation of MC-LR and anatoxin-A was assessed in the $\mathrm{pH}$ ranges of 3.0 to 10.0 (Figure 4e,f). As is well-known, because the $\mathrm{pH}$ of reaction media controls the surface-charge properties of photocatalysts and the speciation of cyanotoxins, it plays a pivotal role in the adsorption and photocatalytic degradation of cyanotoxins. In our study, the isoelectric points of $\mathrm{ZnO}$ and $\mathrm{A} 5 \mathrm{ZO}$ were identified to be $\mathrm{pH} 8.8$ and $\mathrm{pH} 9.0$, respectively. Such findings suggest that, when the $\mathrm{pH}$ is less than the isoelectric point, the surface is positively charged; when the $\mathrm{pH}$ equals the isoelectric point, the surface is neutral; and when the $\mathrm{pH}$ is greater than the isoelectric point, the surface is negatively charged. By comparison, MC-LR was positively charged when the $\mathrm{pH}$ was less than 2.09 neutral when the $\mathrm{pH}$ ranged between 2.09 and 2.19, and negatively charged when the $\mathrm{pH}$ was higher than 2.19 [9]. However, anatoxin-A, the dominant species of this cyanotoxin, was neutral at a $\mathrm{pH}$ less than 9.36 [9].

As shown in Figure 4e, the photocatalytic degradation of MC-LR was higher and virtually identical after 80 min of visible-LED irradiation at pH 3.0 to 7.0, when the photocatalyst surface was positively charged and the dominant species of MC-LR in the reactant media was negatively charged. As expected, further increases in $\mathrm{pH}$ translated into less photocatalytic degradation when both the photocatalyst's surface and the cyanotoxins were negatively charged, which promoted the electrostatic repulsion, while hindering the interaction between both entities. By contrast, the maximum photocatalytic degradation of anatoxin-A occurred at $\mathrm{pH} 9.0$ (i.e., $99.8 \pm 0.2 \%$ ) to 10.0 (i.e., $99.6 \pm 0.4 \%$ ), when $\mathrm{A} 5 \mathrm{ZO}$ was negatively charged and anatoxin-A was neutral (Figure 4f). At a pH lower than 9.0, because both $\mathrm{A} 5 \mathrm{ZO}$ and anatoxin-A were negatively charged, the interaction between the entities was unfavorable, which effectively reduced the efficiency of photocatalytic degradation. Taken together, it is well-known that acidic media are not optimal for $\mathrm{ZnO}$, because they affect the photocatalyst's stability as a result of $\mathrm{ZnO}^{\prime}$ s dissolution. However, in the presence of cyanobacterial blooms, the $\mathrm{pH}$ of bodies of water increases and can exceed 8.0, due to the consumption of dissolved $\mathrm{CO}_{2}$. Thus, the photocatalytic degradation of cyanotoxins is necessary and has to be efficient at $\mathrm{pH}$ levels close to neutral or slightly alkaline [9].

The aim of treating water photocatalytically is to completely mineralize pollutants-in our case, cyanotoxins. The photocatalytic degradation of MC-LR and anatoxin-A produces numerous organic intermediates as they mineralize [9,31-34]. As shown in Figure 5, the mineralization of MC-LR after $180 \mathrm{~min}$ of visible-LED irradiation was less than $50 \%$ of the theoretical amount expected for complete mineralization at $\mathrm{pH} \leq 7.0$. In the case of anatoxin-A, practically complete mineralization occurred at $\mathrm{pH} \geq 9.0$ after $180 \mathrm{~min}$ of visible-LED irradiation. Such results imply that the mechanism of MC-LR's degradation is more complex than the one proposed for anatoxin-A. The complete mineralization of both cyanotoxins was confirmed after $380 \mathrm{~min}$ of visible-LED irradiation. At the same time, the reported values are highly competitive with outcomes achieved with state- 
of-the-art photocatalytic techniques for mineralizing cyanotoxins [9,12,13,31,35-37]. By contrast, most studies on the photocatalytic degradation of cyanotoxins have not involved analyzing mineralization but only the degradation of the initial cyanotoxins, often without considering that some by-products and/or intermediates could be as harmful as the cyanotoxins $[9,12,13,31,35-37]$.

a

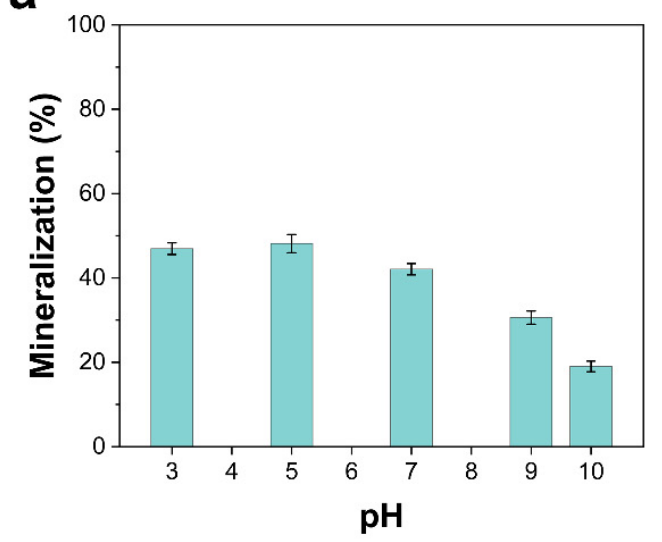

b

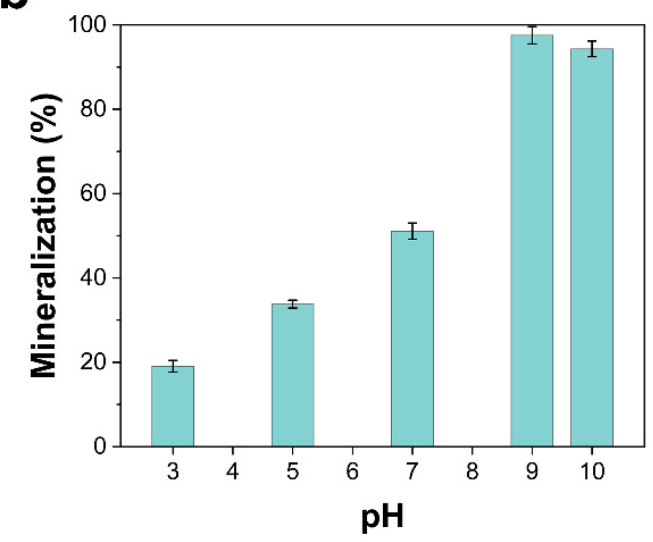

Figure 5. Mineralization (180 min) as a function of $\mathrm{pH}$ for AZO nanoparticle photocatalysts (photocatalyst dosage $=0.5 \mathrm{~g} \mathrm{~L}^{-1}$ ) of (a) microcystin-LR and (b) anatoxin-A under visible-light-emitting-diode irradiation at $20^{\circ} \mathrm{C}$. Error bars indicate standard deviations of the four replicated experiments.

It is significant that the cost associated with the photocatalytic treatment of cyanotoxins (or organic pollutants in general) is typically translated directly to the energy consumption, which is closely related to the wattage of the lamp. Therefore, the use of visible-LED irradiation should reduce the energy consumption versus conventional light sources. However, large-scale experiments, incorporation of photocatalysts in reactors, photocatalytic reactor design, and water-matrix effects, among others, must be necessarily considered to predict costs $[9,38-41]$.

\subsection{Photocatalyst Reusability}

The reusability and stability of A5ZO nanoparticles in the degradation of MC-LR at $\mathrm{pH} 7.0$ and anatoxin- $\mathrm{A}$ at $\mathrm{pH} 9.0$ were also investigated. Figure 6a shows the five consecutive cyclic photocatalytic degradations of both cyanotoxins after 80 min irradiation under visible LED. For MC-LR, the efficiency of photocatalytic degradation dropped significantly after five cycles, possibly due to the adsorption of by-products formed during MC-LR's degradation, which results in photocatalyst poisoning. At pH 7.0, MC-LR's mineralization after $80 \mathrm{~min}$ of irradiation was less than $20 \pm 2 \%$. Conversely, the photocatalytic degradation of anatoxin-A was virtually constant during the $80 \mathrm{~min}$ of five consecutive cycles of irradiation, as well as especially efficient (i.e., $98 \pm 2 \%$ ) with A5ZO. By contrast, at $\mathrm{pH} 9.0$, the mineralization of anatoxin-A after $80 \mathrm{~min}$ of visible-LED irradiation was approximately $67 \pm 2 \%$. The different mineralization rate of MC-LR at $\mathrm{pH} 7.0$ and anatoxin- $\mathrm{A}$ at $\mathrm{pH} 9.0$ seemed to affect the reusability of $\mathrm{A} 5 \mathrm{ZO}$, which was higher when the rate of mineralization was greater. 
a

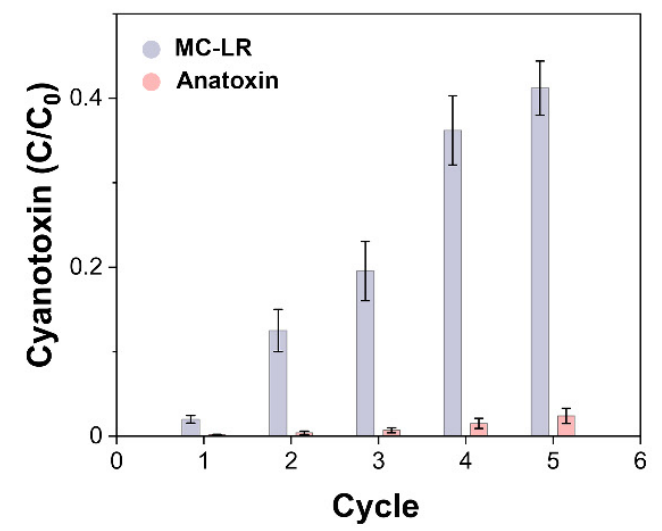

b

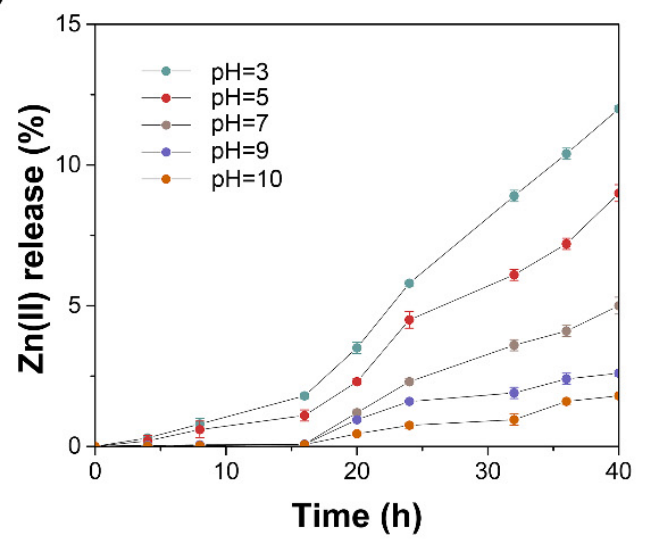

Figure 6. (a) Degradation of MC-LR at pH 7.0 and anatoxin-A at pH 9.0, in five consecutive reusability experiments with A5ZO nanoparticle photocatalysts (photocatalyst dosage $=0.5 \mathrm{~g} \mathrm{~L}^{-1}$ ), after $80 \mathrm{~min}$ of visible light-emitting diode (LED) irradiation at $20^{\circ} \mathrm{C}$. (b) Time-dependent concentration of $\mathrm{Zn}$ (II) ions from A5ZO at different pH levels during $40 \mathrm{~h}$ of visible-LED irradiation at $20^{\circ} \mathrm{C}$. Error bars indicate standard deviations of the four replicated experiments.

The chemical and photochemical stability of A5ZO was also investigated by analyzing the $\mathrm{Zn}(\mathrm{II})$ and $\mathrm{Al}(\mathrm{III})$ released in aqueous media at different $\mathrm{pH}$ levels for $40 \mathrm{~h}$ of visible-LED irradiation. ZnO's well-known photocorrosive behavior occurs under UV and visible-light irradiation, and at extreme $\mathrm{pH}$ values (i.e., $2.0<\mathrm{pH}>10.0$ ), $\mathrm{ZnO}$ even dissolves, which of course defeats its purpose in photocatalysis [39]. However, corrosion and photocorrosion can be suppressed via surface modification or doping strategies. As shown in Figure 6b, the corrosion and photocorrosion of A5ZO nanoparticles were minimal in weak alkaline conditions and moderate at neutral $\mathrm{pH}$. Importantly, no $\mathrm{Al}(\mathrm{III})$ species in the aqueous medium were detected during the $40 \mathrm{~h}$ of visible-LED irradiation. Such findings matter because cyanotoxins are usually generated in neutral or slightly alkaline bodies of water. The findings also confirm the stability of synthesized A5ZO photocatalysts in the photocatalytic degradation of cyanotoxins from natural bodies of water.

\section{Conclusions}

In search of a complementary economic gain relative to energy consumption, we examined the photocatalytic activity of Al-doped $\mathrm{ZnO}$ nanoparticles in degrading and mineralizing two cyanotoxins under visible-LED irradiation. The sol-gel method was found to be as reproducible method of synthetizing well-defined Al-doped $\mathrm{ZnO}$ nanoparticles with controlled percentages of $\mathrm{Al}$, namely ranging from 0 to 5 at.\%. Doping has a twofold effect: It reducing bandgaps, thus widening the visible activity; and it minimizes deleterious photocorrosion, that is, the easy photochemical dissolution of zinc oxide.

Increasing the dosage of photocatalyst in the solution did not exert a linear effect on the photocatalytic activity. Upon having a certain amount of photocatalyst, photocatalytic activity increased; however, similar behavior was observed from a threshold value as well $\left(0.5 \mathrm{~g} \mathrm{~L}^{-1}\right)$. Considering that the easy agglomeration of the nanoparticles could have been responsible, we pragmatically decided that a dose of $0.5 \mathrm{~g} \mathrm{~L}^{-1}$ could maximize efficacy and save material.

Among other findings, the $\mathrm{pH}$ of the solution for mineralizing cyanotoxins was critical. The optimal $\mathrm{pH}$ is the one that favors the interaction of the substrate and the photocatalyst, which itself relates to the surface charge of the species. Because the $\mathrm{pH}$ value is responsible for the molecule's chemical form, and thus its electrical charge, the value of the isoelectric point of the species proved critical as well. According to our results, the best $\mathrm{pH}$ value for solutions for mineralizing anatoxin-A is 9.0, under which conditions mineralization completed, and for MC-LR is $\mathrm{pH} \mathrm{7.0,} \mathrm{under} \mathrm{which} \mathrm{conditions} \mathrm{the} \mathrm{reaction} \mathrm{yield} \mathrm{became}$ balanced with the photocatalyst's chemical stability. The reusability of the photocatalysts 
also depended on the entities and reaction conditions. In any case, neutral or weak alkaline media are best suited to avoiding the risk of the photocorrosion or dissolution of the photocatalyst, as has been proven by controlling the release of $\mathrm{Zn}(\mathrm{II})$.

The results additionally show that the photocatalytic activity of the synthesized photocatalysts was greater than that previously reported for degradation of cyanotoxins. Even when mineralization remains incomplete, as was the case with MC-LR, degrading a high percentage of any pollutant benefits the environment, because the intermediatereaction products exert lower harmful effects on water.

\section{Materials and Methods}

\subsection{Synthesis of Nanoparticles}

Al-doped $\mathrm{ZnO}$ nanopowders were elaborated via the sol-gel method, as shown in Scheme 1. We dissolved $16 \mathrm{~g}$ of zinc acetate dihydrate $\left(\mathrm{Zn}\left(\mathrm{CH}_{3} \mathrm{COO}\right)_{2} \cdot 2 \mathrm{H}_{2} \mathrm{O} ; \geq 99.0 \%\right.$, Sigma-Aldrich) in $112 \mathrm{~mL}$ of methanol (99.8\%, Sigma-Aldrich), which acted as solvent. The solution was stirred for $10 \mathrm{~min}$, at room temperature, after which we added an adequate quantity of aluminum nitrate-9-hydrate ( $\geq 98 \%$, Sigma-Aldrich) as a dopant precursor, according to $\mathrm{Al}: \mathrm{Zn}$ atomic ratios of $0 \%, 1 \%, 3 \%$, and $5 \%$. The obtained solutions were stirred for $15 \mathrm{~min}$ and placed in an autoclave, to dry in the supercritical condition of ethyl alcohol. Last, the synthesized powders were calcined for $2 \mathrm{~h}$, using an air muffle furnace at $400{ }^{\circ} \mathrm{C}$.

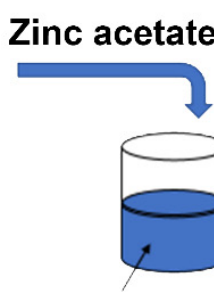

Methanol

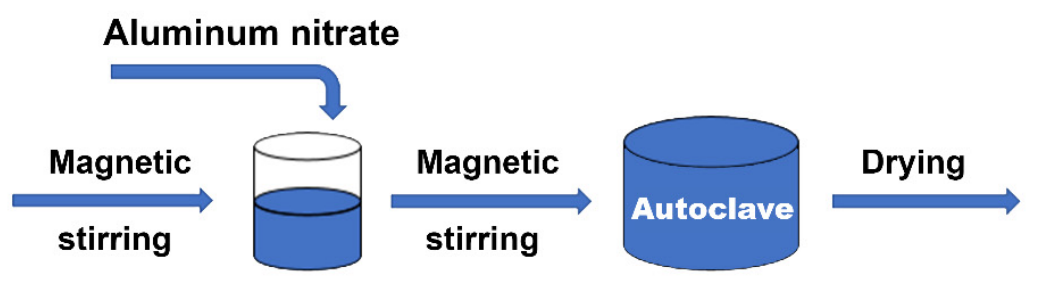

\section{Al-doped Zno nanopowders}

Scheme 1. Synthesis of AZO nanoparticles by the sol-gel method.

\subsection{Materials Characterization}

The surface morphology, crystalline structure, and optical properties of ZnO-based photocatalysts were investigated by TEM, XRD, and PL measurements. First, we studied the microstructure of the samples by using an XRD machine (Bruker AXS D8 Advance, MA, USA), at the wavelength of $C u K \alpha$ (i.e., $1.5405 \AA$ ). The network parameters $(a, c)$ and the unit cell volume $(V)$ were determined by using the following equations $[23,24]$ :

$$
\begin{gathered}
a=\frac{\lambda}{\sqrt{3} \sin \theta_{(100)}} \\
c=\frac{\lambda}{\sin \theta_{(002)}} \\
V=\frac{\sqrt{3}}{2} a^{2} \cdot c
\end{gathered}
$$

where $\lambda$ is the wavelength of the radiation used (i.e., $1.54060 \AA$ for $C u K \alpha$ ) and $\theta$ is the Bragg diffraction angle. The calculated lattice parameters values $(a, c)$ and the concluded unit cell volume $(V)$ are presented in Table 1 . The micro-deformations $(\varepsilon)$ were estimated according to the Williamson-Hall model [25]:

$$
\beta \cos \theta=\frac{k \lambda}{D}+4 \varepsilon \sin \theta
$$


The plot of $(\beta \cos \theta)$ versus $(4 \sin \theta)$ for the $\mathrm{ZnO}$ nanopowder, as shown in Figure 1 , was fitted according to Equation (4). The $D$ value was estimated from the slope of the extrapolation of the linear fit, while the $\varepsilon$ value was given by the fit slope. In addition, the dislocation density $(\delta)$ was calculated by using the following relationship [26]:

$$
\delta=\frac{15 \varepsilon}{a D}
$$

Next, the shapes and sizes of the prepared nanoparticles were examined with a transmission electron microscope (JEOL JEM 2010, Tokyo, Japan), an LaB6 electron gun that operates at 200, which was equipped with a Gatan 794 MultiScan CCD camera used to view the digital images. The Brunauer-Emmett-Teller (BET) surface area of each photocatalyst was determined by using the $\mathrm{N}_{2}$ adsorption-desorption isotherms obtained at $77 \mathrm{~K}$, using a Micrometrics Tristar-II (Micrometrics, Canada). The UV-vis diffuse reflectance spectra (DRS) were recorded by using a Lambda 900 UV spectrophotometer (PerkinElmer, Waltham, MA, USA). Last, a NanoLog Horiba modular spectrofluorometer (Horiba, Kyoto, Japan) used for PL measurements was equipped with an Xe lamp, as the excitation light source, with a wavelength of $325 \mathrm{~nm}$, at room temperature. Emissions were studied between 350 and $800 \mathrm{~nm}$.

\subsection{Photocatalytic Activity}

To examine the photocatalytic activity of the Al-doped $\mathrm{ZnO}$ nanoparticles, the photocatalytic degradation of single-pollutant aqueous solutions of $1.25 \mathrm{mg} \mathrm{L}^{-1} \mathrm{MC}$-LR (SigmaAldrich) and $2.5 \mathrm{mg} \mathrm{L}^{-1}( \pm$ )-anatoxin-A fumarate (Hello Bio Ltd., >99\%) was observed under irradiation from three $6.2 \mathrm{~W}$ LEDs (irradiance $=65 \mathrm{~mW} \mathrm{~cm}^{-2}$; energy consumption $=7 \mathrm{kWh}$ or $1000 \mathrm{~h}$ ) for $80 \mathrm{~min}$. The photocatalytic experiments were conducted in a quartz dish reactor (volume $=40 \mathrm{~mL}$, diameter $=10 \mathrm{~cm}$ ) sealed with a quartz cover and cooled with fans, to prevent the evaporation of the solution. All the experiments were performed in quadruplicate. Different dosages of Al-doped ZnO nanoparticles (i.e., 0.25, 0.5, 0.75, and $1.0 \mathrm{~g} \mathrm{~L}^{-1}$ ) were ultrasonically (power $=5 \mathrm{~W} \mathrm{~L}^{-1}$; time $=60 \mathrm{~s}$ ) suspended in the pollutant solution, to determine the effect of the dosage of the photocatalyst. To examine the effect of $\mathrm{pH}$ on the photocatalytic degradation of the cyanotoxins, the initial solution's $\mathrm{pH}$ was adjusted to $3.0,5.0,7.0,9.0$, and 10.0 with $0.1 \mathrm{M} \mathrm{HCl}$ or $\mathrm{NaOH}$ solutions. Before irradiation commenced, the suspensions were magnetically stirred at $200 \mathrm{rpm}$, in dark conditions, in the presence of each cyanotoxin, for $1 \mathrm{~h}$, in order to achieve adsorption-desorption equilibrium. Once achieved, the suspensions were irradiated with visible light by way of continuous magnetic stirring. With the temperature maintained at $20^{\circ} \mathrm{C}$, samples $(500 \mu \mathrm{L})$ were taken at specified times and filtered through a syringe filter $(0.02 \mu \mathrm{m}$, Whatman $)$, to separate the photocatalyst. The temporal photocatalytic degradation of cyanotoxins was monitored by quantifying the reduction of the concentration of MC-LR and anatoxin-A, using a high-performance liquid chromatograph (Agilent; Santa Clara, CA, USA) with a photodiode array detector set at $238 \mathrm{~nm}$ and ultrahigh-performance liquid chromatography (Thermo Fisher Scientific; Waltham, MA, USA), respectively.

To quantify MC-LR, a C18 Discovery HS column $150 \mathrm{~mm}$ by $2.1 \mathrm{~mm}$ i.d. for particles $5 \mu \mathrm{m}$ in size (Supelco, Inc.; Bellefonte, PA, USA) was used for the stationary and mobile phases; it consisted of $0.05 \%(v / v)$ trifluoroacetic acid in Milli-Q water and $0.05 \%$ trifluoroacetic acid in acetonitrile in a ratio of 60:40. Analysis was performed under equilibrium conditions at a column temperature of $40^{\circ} \mathrm{C}$, a flow rate of $0.2 \mathrm{~mL} \mathrm{~min}^{-1}$, and an injection volume of $20 \mu \mathrm{L}$ [40]. By contrast, to quantify anatoxin-A, a Kinetex HILIC column measuring $100 \mathrm{~mm}$ by $2.1 \mathrm{~mm}$ i.d. for particles $2.6 \mu \mathrm{m}$ in size (Phenomenex, Inc.; Basel, Switzerland) was employed for the stationary phase, while the mobile phase consisted of $95 \%(v / v)$ acetonitrile $+5 \%(v / v)$ aqueous solution (i.e., $2 \mathrm{mM}$ ammonium formate $+3.6 \mathrm{mM}$ formic acid) and an aqueous solution of $2 \mathrm{mM}$ ammonium formate and $3.6 \mathrm{mM}$ formic acid in a ratio of 85:15 [12]. The analysis was performed under equilibrium conditions, with a column temperature of $25^{\circ} \mathrm{C}$, a flow rate of $0.2 \mathrm{~mL} \mathrm{~min}^{-1}$, and an injection volume of $20 \mu \mathrm{L}$. 
Last, the mineralization of cyanotoxins was determined by comparing the reduction of total organic content (TOC) after $180 \mathrm{~min}$ of visible LED irradiation, using a TOC analyzer (Shimadzu; Nakagyo-ku, Kyoto, Japan). The photocatalytic experiments for each catalyst were performed in quadruplicate.

\subsection{Photocatalyst Reusability}

To evaluate the reusability of the Al-doped $\mathrm{ZnO}$ nanoparticles, the photocatalytic degradation of MC-LR (Sigma-Aldrich) and ( \pm )-anatoxin-A fumarate was analyzed by reusing the same photocatalyst sample, under the same reaction conditions, during five consecutive $80 \mathrm{~min}$ irradiation cycles. For comparison, the photocatalytic degradation of cyanotoxins was also determined by liquid chromatography after 80 min of visible LED irradiation. After each experiment, the Al-doped nanoparticles were recuperated by centrifugation, washed, and reused. Meanwhile, photostability was analyzed by quantifying the time-dependent evolution concentration of $\mathrm{Zn}$ (II) ions in $40 \mathrm{~mL}$ Milli-Q water, under visible LED irradiation for $8 \mathrm{~h}$. The initial solution's $\mathrm{pH}$ was adjusted to 3.0, 5.0, 7.0, 9.0, and 10.0 with $0.1 \mathrm{M} \mathrm{HCl}$ or $\mathrm{NaOH}$ solutions. At different times during the $40 \mathrm{~h}$ period, $0.5 \mathrm{~mL}$ of irradiated solution was filtered through a syringe filter $(0.02 \mu \mathrm{m}$, Whatman), to separate the photocatalyst. The concentration of $\mathrm{Zn}$ (II) ions was determined spectrophotometrically by using Zincon monosodium salt (Sigma-Aldrich) in borate buffer (50 mM, $\mathrm{pH}=9$ ) and measuring the absorbance associated with the $\mathrm{Zn}(\mathrm{II})$-bound Zincon complex at $620 \mathrm{~nm}[42,43]$. For those measurements, a UV-1800 Shimadzu UV-vis spectrophotometer (Shimadzu; Japan), accompanied by a quartz cuvette with an optical length of $1 \mathrm{~cm}$, was used. The $\mathrm{Al}(\mathrm{III})$ concentration was determined by ICP-OES analysis. The dosage of the photocatalyst for all experiments described in this section was set at $0.5 \mathrm{~g} \mathrm{~L}^{-1}$. The reusability experiments were performed in quadruplicate.

Author Contributions: Conceptualization, M.B., E.G., R.D., and A.S.; methodology, M.B., and A.S.; validation, E.G., R.D., and A.S.; formal analysis, M.B., E.G., R.D., and A.S.; investigation, M.B., and A.S.; resources, E.G., R.D., and A.S.; data curation, M.B. and A.S.; writing-original draft preparation, M.B. and A.S.; writing — review and editing, E.G., R.D., and A.S.; supervision, E.G., R.D., and A.S.; project administration, E.G., R.D., and A.S.; funding acquisition, E.G., and R.D. All authors have read and agreed to the published version of the manuscript.

Funding: This work was partially supported by the Metrohm foundation. Partial funding from the TEC2017-85059-C3-2-R project (co-financed by the Fondo Europeo de Desarrollo Regional, FEDER) from the Spanish Ministerio de Economía y Competitividad (MINECO) is also acknowledged. Albert Serrà would like to acknowledge funding from the EMPAPOSTDOCS-II program. The EMPAPOSTDOCSII program has received funding from the European Union's Horizon 2020 research and innovation program under the Marie Skłodowska-Curie grant agreement, number 754364.

Data Availability Statement: Data is contained within the article.

Conflicts of Interest: The authors declare no conflict of interest.

\section{References}

1. Huisman, J.; Codd, G.A.; Paerl, H.W.; Ibelings, B.W.; Verspagen, J.M.H.; Visser, P.M. Cyanobacterial blooms. Nat. Rev. Microbiol. 2018, 16, 471-483. [CrossRef] [PubMed]

2. Buratti, F.M.; Manganelli, M.; Vichi, S.; Stefanelli, M.; Scardala, S.; Testai, E.; Funari, E. Cyanotoxins: Producing organisms, occurrence, toxicity, mechanism of action and human health toxicological risk evaluation. Arch. Toxicol. 2017, 91, 1049-1130. [CrossRef] [PubMed]

3. Dittmann, E.; Wiegand, C. Cyanobacterial toxins-Occurrence, biosynthesis and impact on human affairs. Mol. Nutr. Food Res. 2006, 50, 7-17. [CrossRef] [PubMed]

4. Meriluoto, J.; Blaha, L.; Bojadzija, G.; Bormans, M.; Brient, L.; Codd, G.A.; Drobac, D.; Faassen, E.J.; Fastner, J.; Hiskia, A.; et al. Toxic cyanobacteria and cyanotoxins in European waters-Recent progress achieved through the CYANOCOST action and challenges for further research. Adv. Oceanogr. Limnol. 2017, 8, 161-178. [CrossRef]

5. Liu, Y.; Chen, W.; Li, D.; Huang, Z.; Shen, Y.; Liu, Y. Cyanobacteria-/cyanotoxin-contaminations and eutrophication status before Wuxi Drinking Water Crisis in Lake Taihu, China. J. Environ. Sci. 2011, 23, 575-581. [CrossRef] 
6. Gkelis, S.; Zaoutsos, N. Cyanotoxin occurrence and potentially toxin producing cyanobacteria in freshwaters of Greece: A multi-disciplinary approach. Toxicon 2014, 78, 1-9. [CrossRef]

7. Ibelings, B.W.; Backer, L.C.; Kardinaal, W.E.A.; Chorus, I. Current approaches to cyanotoxin risk assessment and risk management around the globe. Harmful Algae 2014, 40, 63-74. [CrossRef]

8. Du, X.; Liu, H.; Yuan, L.; Wang, Y.; Ma, Y.; Wang, R.; Chen, X.; Losiewicz, M.D.; Guo, H.; Zhang, H. The diversity of cyanobacterial toxins on structural characterization, distribution and identification: A systematic review. Toxins 2019, 11, 530. [CrossRef]

9. Serrà, A.; Philippe, L.; Perreault, F.; Garcia-Segura, S. Photocatalytic treatment of natural waters. Reality or hype? The case of cyanotoxins remediation. Water Res. 2020, 188, 116543. [CrossRef]

10. Christoffersen, K.; Kaas, H. Toxic Cyanobacteria in Water. A Guide to Their Public Health Consequences, Monitoring, and Management; CRC Press: London, UK, 2000; Volume 45, ISBN 0419239308.

11. Berry, M.A.; Davis, T.W.; Cory, R.M.; Duhaime, M.B.; Johengen, T.H.; Kling, G.W.; Marino, J.A.; Den Uyl, P.A.; Gossiaux, D.; Dick, G.J.; et al. Cyanobacterial harmful algal blooms are a biological disturbance to Western Lake Erie bacterial communities. Environ. Microbiol. 2017, 19, 1149-1162. [CrossRef]

12. Serrà, A.; Pip, P.; Gómez, E.; Philippe, L. Efficient magnetic hybrid ZnO-based photocatalysts for visible-light-driven removal of toxic cyanobacteria blooms and cyanotoxins. Appl. Catal. B Environ. 2020, 268, 118745. [CrossRef]

13. Schneider, M.; Bláha, L. Advanced oxidation processes for the removal of cyanobacterial toxins from drinking water. Environ. Sci. Eur. 2020, 32. [CrossRef]

14. Zhang, G.; Nadagouda, M.N.; O'Shea, K.; El-Sheikh, S.M.; Ismail, A.A.; Likodimos, V.; Falaras, P.; Dionysiou, D.D. Degradation of cylindrospermopsin by using polymorphic titanium dioxide under UV-Vis irradiation. Catal. Today 2014, 224, 49-55. [CrossRef]

15. Antoniou, M.G.; Zhao, C.; O'Shea, K.E.; Zhang, G.; Dionysiou, D.D.; Zhao, C.; Han, C.; Nadagouda, M.N.; Choi, H.; Fotiou, T.; et al. Photocatalytic Degradation of Organic Contaminants in Water: Process Optimization and Degradation Pathways; The Royal Society of Chemistry: London, UK, 2016; Volume 2016, ISBN 9781782620419.

16. Mauter, M.S.; Zucker, I.; Perreault, F.; Werber, J.R.; Kim, J.H.; Elimelech, M. The role of nanotechnology in tackling global water challenges. Nat. Sustain. 2018, 1, 166-175. [CrossRef]

17. Antoniou, M.G.; Shoemaker, J.A.; de la Cruz, A.A.; Dionysiou, D.D. LC/MS/MS structure elucidation of reaction intermediates formed during the $\mathrm{TiO}_{2}$ photocatalysis of microcystin-LR. Toxicon 2008, 51, 1103-1118. [CrossRef]

18. Lawton, L.A.; Robertson, P.K.J.; Cornish, B.J.P.A.; Marr, I.L.; Jaspars, M. Processes influencing surface interaction and photocatalytic destruction of microcystins on titanium dioxide photocatalysts. J. Catal. 2003, 213, 109-113. [CrossRef]

19. Loeb, S.K.; Alvarez, P.J.J.; Brame, J.A.; Cates, E.L.; Choi, W.; Crittenden, J.; Dionysiou, D.D.; Li, Q.; Li-Puma, G.; Quan, X.; et al. The Technology Horizon for Photocatalytic Water Treatment: Sunrise or Sunset? Environ. Sci. Technol. 2019, 53, $2937-2947$. [CrossRef]

20. Serrà, A.; Philippe, L. Simple and scalable fabrication of hairy ZnO@ZnS core@shell Cu cables for continuous sunlight-driven photocatalytic water remediation. Chem. Eng. J. 2020, 401, 126164. [CrossRef]

21. Pirhashemi, M.; Habibi-Yangjeh, A.; Rahim Pouran, S. Review on the criteria anticipated for the fabrication of highly efficient ZnO-based visible-light-driven photocatalysts. J. Ind. Eng. Chem. 2018, 62, 1-25. [CrossRef]

22. Serrà, A.; Zhang, Y.; Sepúlveda, B.; Gómez, E.; Nogués, J.; Michler, J.; Philippe, L. Highly reduced ecotoxicity of ZnO-based micro/nanostructures on aquatic biota: Influence of architecture, chemical composition, fixation, and photocatalytic efficiency. Water Res. 2020, 169, 115210. [CrossRef]

23. Karthika, K.; Ravichandran, K. Tuning the Microstructural and Magnetic Properties of ZnO Nanopowders through the Simultaneous Doping of Mn and Ni for Biomedical Applications. J. Mater. Sci. Technol. 2015, 31, 1111-1117. [CrossRef]

24. Kahouli, M.; Barhoumi, A.; Bouzid, A.; Al-Hajry, A.; Guermazi, S. Structural and optical properties of ZnO nanoparticles prepared by direct precipitation method. Superlattices Microstruct. 2015, 85, 7-23. [CrossRef]

25. Reddy, A.J.; Kokila, M.K.; Nagabhushana, H.; Chakradhar, R.P.S.; Shivakumara, C.; Rao, J.L.; Nagabhushana, B.M. Structural, optical and EPR studies on ZnO:Cu nanopowders prepared via low temperature solution combustion synthesis. J. Alloys Compd. 2011, 509, 5349-5355. [CrossRef]

26. Kahraman, S.; Çetinkara, H.A.; Bayansal, F.; Çakmak, H.M.; Güder, H.S. Characterisation of ZnO nanorod arrays grown by a low temperature hydrothermal method. Philos. Mag. 2012, 92, 2150-2163. [CrossRef]

27. Hjiri, M.; El Mir, L.; Leonardi, S.G.; Pistone, A.; Mavilia, L.; Neri, G. Al-doped ZnO for highly sensitive CO gas sensors. Sens. Actuators B Chem. 2014, 196, 413-420. [CrossRef]

28. Han, N.; Chai, L.; Wang, Q.; Tian, Y.; Deng, P.; Chen, Y. Evaluating the doping effect of Fe, Ti and Sn on gas sensing property of ZnO. Sens. Actuators B Chem. 2010, 147, 525-530. [CrossRef]

29. Han, N.; Hu, P.; Zuo, A.; Zhang, D.; Tian, Y.; Chen, Y. Photoluminescence investigation on the gas sensing property of ZnO nanorods prepared by plasma-enhanced CVD method. Sens. Actuators B Chem. 2010, 145, 114-119. [CrossRef]

30. Ding, J.J.; Chen, H.X.; Ma, S.Y. Structural and photoluminescence properties of Al-doped ZnO films deposited on Si substrate. Phys. E Low-Dimens. Syst. Nanostruct. 2010, 42, 1861-1864. [CrossRef]

31. Pinho, L.X. Photocatalytic Degradation of Cyanobacteria and Cyanotoxins Using Suspended and Immobilized TiO 2 . Ph.D. Thesis, University of Porto, Porto, Portugal, 2014; p. 168.

32. Hu, X.; Hu, X.; Tang, C.; Wen, S.; Wu, X.; Long, J.; Yang, X.; Wang, H.; Zhou, L. Mechanisms underlying degradation pathways of microcystin-LR with doped $\mathrm{TiO}_{2}$ photocatalysis. Chem. Eng. J. 2017, 330, 355-371. [CrossRef] 
33. Andersen, J.; Han, C.; O'Shea, K.; Dionysiou, D.D. Revealing the degradation intermediates and pathways of visible light-induced $\mathrm{NF}^{-\mathrm{TiO}_{2}}$ photocatalysis of microcystin-LR. Appl. Catal. B Environ. 2014, 154-155, 259-266. [CrossRef]

34. Antoniou, M.G.; de la Cruz, A.A.; Dionysiou, D.D. Degradation of microcystin-LR using sulfate radicals generated through photolysis, thermolysis and e- transfer mechanisms. Appl. Catal. B Environ. 2010, 96, 290-298. [CrossRef]

35. Likodimos, V.; Han, C.; Pelaez, M.; Kontos, A.G.; Liu, G.; Zhu, D.; Liao, S.; De La Cruz, A.A.; O'Shea, K.; Dunlop, P.S.M.; et al Anion-doped $\mathrm{TiO}_{2}$ nanocatalysts for water purification under visible light. Ind. Eng. Chem. Res. 2013, 52, 13957-13964. [CrossRef]

36. Antoniou, M.G.; Boraei, I.; Solakidou, M.; Deligiannakis, Y.; Abhishek, M.; Lawton, L.A.; Edwards, C. Enhancing photocatalytic degradation of the cyanotoxin microcystin-LR with the addition of sulfate-radical generating oxidants. J. Hazard. Mater. 2018, 360, 461-470. [CrossRef] [PubMed]

37. Zhao, C.; Li, D.; Liu, Y.; Feng, C.; Zhang, Z.; Sugiura, N.; Yang, Y. Photocatalytic removal of microcystin-LR by advanced WO3-based nanoparticles under simulated solar light. Sci. World J. 2015, 2015. [CrossRef] [PubMed]

38. Brillas, E.; Serrà, A.; Garcia-Segura, S. Biomimicry designs for photoelectrochemical systems: Strategies to improve light delivery efficiency. Curr. Opin. Electrochem. 2021, 26, 100660. [CrossRef]

39. Serrà, A.; Gómez, E.; Philippe, L. Bioinspired ZnO-based solar photocatalysts for the efficient decontamination of persistent organic pollutants and hexavalent chromium in wastewater. Catalysts 2019, 9, 974. [CrossRef]

40. Zhang, G.; Zhang, Y.C.; Nadagouda, M.; Han, C.; O'Shea, K.; El-Sheikh, S.M.; Ismail, A.A.; Dionysiou, D.D. Visible light-sensitized $\mathrm{S}, \mathrm{N}$ and $\mathrm{C}$ co-doped polymorphic $\mathrm{TiO}_{2}$ for photocatalytic destruction of microcystin-LR. Appl. Catal. B Environ. 2014, 144, 614-621. [CrossRef]

41. Serrà, A.; Gómez, E.; Michler, J.; Philippe, L. Facile cost-effective fabrication of $\mathrm{Cu} @ \mathrm{Cu}_{2} \mathrm{O} @ \mathrm{CuO}-$ microalgae photocatalyst with enhanced visible light degradation of tetracycline. Chem. Eng. J. 2021, 127477. [CrossRef]

42. Säbel, C.E.; Neureuther, J.M.; Siemann, S. A spectrophotometric method for the determination of zinc, copper, and cobalt ions in metalloproteins using Zincon. Anal. Biochem. 2010, 397, 218-226. [CrossRef]

43. Serrà, A.; Artal, R.; García-Amorós, J.; Sepúlveda, B.; Gómez, E.; Nogués, J.; Philippe, L. Hybrid Ni@ZnO@ZnS-Microalgae for Circular Economy: A Smart Route to the Efficient Integration of Solar Photocatalytic Water Decontamination and Bioethanol Production. Adv. Sci. 2020, 7, 1-9. [CrossRef] 